\title{
A Case for Mixed Methods Research in Massage Therapy
}

\author{
Amanda Baskwill, MSc, BED, RMT \\ PC Massage Therapy, School of Hospitality, Recreation \& Tourism, Humber College, Toronto, ON, Canada
}

Massage therapy (MT) research is sometimes thought of by massage therapists as more about proving to other health care providers that massage therapy is effective than creating a better understanding of what massage therapists do and how they do it. ${ }^{(1)}$ This may lead to a preference for quantitative research results that have also been valued by other health care providers. Ninety-five percent of massage therapists believe that research can help massage therapists to become more highly valued professionals. ${ }^{(1)}$ Unfortunately, the body of literature for MT is described by the National Centre for Complementary and Integrative Health ${ }^{(2)}$ as "preliminary" and "conflicting" and may be a barrier to enhancing the credibility of MT. (1) The potential of MT research to support the profession's image in the eyes of other health care providers and the public requires MT researchers to reconsider current methods. This article discusses the potential of mixed methods research to contribute to what is known about MT.

In the clinical decision-making model used by massage therapists, ${ }^{(3)}$ collecting both subjective and objective information from a patient is the foundation of the evaluation phase. This, combined with the complexity of MT care (patient-therapist interaction, provision of intimate care, inconclusive research on mechanisms of action for techniques, and variation in naming and application of massage techniques), makes the argument for mixed methods research compelling.

\section{FUNDAMENTALS OF MIXED METHODS RESEARCH}

Mixed methods research (MMR) is recommended when investigating complex problems, and combines qualitative and quantitative methods. ${ }^{(4)}$ While quantitative methods are informed by a positivist philosophy and qualitative methods are informed by a constructivist philosophy, mixed methods are informed by a pragmatic philosophy. ${ }^{(5)}$ At its core, pragmatism uses that which works best for the situation at hand. In other words, it allows the research questions to drive the methods used.
Methods can be mixed at the point of the research questions, data collection or data analysis, or all three, with each creating a different way of describing the methodology used. ${ }^{(6)}$ The value of this blending is sometimes the exploration or explanation of the phenomenon of interest when one method would not have produced a fulsome description or analysis. Discussion continues regarding how best to embed, combine, or blend philosophies, data collection, and analysis. ${ }^{(7)}$

A team is often needed to ensure the design is strong from a quantitative, qualitative, and mixed approach in order to ensure the best methodology is chosen for the research question. ${ }^{(8)}$ The combination of methods, and the requirement for a team of researchers and stakeholders, can result in increased costs due to the need to fund a qualitative and quantitative strand of study. ${ }^{(8)}$ These challenges may prevent the broad use of this important type of research method.

To date, few research studies in massage therapy have used mixed methods, ${ }^{(9)}$ despite its potential to explore complex research questions facing the profession. A literature search in PubMed using "mixed methods" OR "combined methods" and "massage [MeSH]" retrieved six articles. Of the six articles retrieved, only three were mixed methods studies. Of the three articles, two looked at professionalization or professionalism issues, and one used MMR to explore a clinical question. MMR methodology has evolved since its inception, and it is time for MT researchers to consider this approach for future investigation of complex questions in all aspects of the profession.

\section{A CALL TO ACTION}

This call to action focuses on three key elements that would support the ability of MT researchers. First is the need for practice-based evidence that better represents massage therapists' patients and interventions. Second is the opportunity for MT education to continue to strengthen the research literacy curriculum and include information about MMR. Finally, prioritization of MMR studies by MT research funders is needed as this type of research is often more timeand resource-intense. 


\section{RESEARCH-BASED PRACTICE NEEDS PRACTICE-BASED RESEARCH}

To support massage therapists' use of evidence in practice, more consideration needs to be given by researchers to the types of research that are more useful for practitioners. Traditional randomized controlled trials (RCTs) are not necessarily useful as participants and interventions do not always represent what is happening in practice, known as low ecological validity. ${ }^{(10)}$ Future efficacy and effectiveness research should strive to enhance not only the ecological validity of the participants and interventions used, but also should consider using MMR. For example, collecting qualitative data from patients during a traditional quantitative trial would be one way to illicit the outcomes valued by patients. ${ }^{(8)}$ Knowing these may allow researchers to choose more meaningful measures in future trials.

\section{MMR IN MT EDUCATION}

MT education varies in its inclusion of research literacy and capacity. While no research has explicitly investigated the status of research curricula, anecdotal information suggests that most programs provide only a cursory introduction to research. The goal is often to support future clinicians to find, read, and understand research. As there are currently few MMR studies in MT, it is understandable that the little time given to research is spent on quantitative, and maybe qualitative, methods. MT educators, program administrators, and owners must make time in their programs to better equip future clinicians not only to find, read, and understand, but to analyze research studies, including MMR. While a fully methodological education is not reasonable, efforts should be made to familiarize students with multiple types of research and encourage them to develop skills to support their continued education in this area once in practice. Establishing a culture of inquiry within MT education programs is fundamental to its development within the profession.

\section{FUNDING TO SUPPORT MMR}

The final element in this call to action is the need for financial support of MT researchers. As mentioned previously, MMR usually requires more time, people, and resources to conduct a reliable, valid, and trustworthy study. As such, MT research funding agencies should give preference to MMR with teams that are adequately trained to conduct this type of research and who seek to answer complex questions facing the MT profession. These complex questions will inevitably be focused on efficacy or effectiveness at first, but going forward, should also consider professionalization, professionalism, and education questions.

\section{SUMMARY}

This call to action recognizes mixed methods research remains controversial despite its increased use in health care. ${ }^{(7,11)}$ However, those who employ this approach see value in mixing, blending or combining the best of qualitative methods with quantitative to create an approach that studies complex problems. To date, few research studies in massage therapy have used mixed methods. ${ }^{(9)}$ MT researchers are challenged to embrace the potential of MMR to explore complex research questions facing the profession. Mixed methods research is often more time- and resource-intense, so should be undertaken when the research question demands that level of complexity. MT researchers who wish to undertake this type of investigation are advised to work with a team with expertise in multiple areas of health research methodology.

\section{COPYRIGHT}

Published under the CreativeCommons AttributionNonCommercial-NoDerivs 3.0 License.

\section{REFERENCES}

1. Shroff FM, Sahota IS. How can massage therapy move forward? Registered massage therapists touch on key points shaping their profession in British Columbia, Canada. Home Health Care Manage Pract. 2012;24(4):182-192.

2. National Centre for Complementary and Integrative Health. Massage therapy for health purposes. Bethesda, MD: NCCIH; 2016. Available from: https://nccih.nih.gov/health/massage/ massageintroduction.htm

3. Andrade CK. Outcome-based Massage: Putting Evidence Into Practice, 3rd ed. Philadelphia, PA: Lippincott Williams \& Wilkins; 2014.

4. Johnson RB, Onwuegbuzie AJ, Turner LA. Toward a definition of mixed methods research. J Mixed Meth Res. 2007;1(2): $112-135$.

5. Teddlie C, Tashakkori A. Foundations of Mixed Methods Research: Integrating Quantitative and Qualitative Approaches in the Social and Behavioural Sciences. Thousand Oaks, CA: SAGE Publications, Inc; 2009.

6. Fetters MD, Curry LA, Creswell JW. Achieving integration in mixed methods designs-principles and practices. Health Serv Res. 2013;48(6 Pt 2):2134-2156.

7. Bergman MM. The good, the bad, and the ugly in mixed methods research and design. $J$ Mixed Meth Res. 2011;5(4): 271-275.

8. Creswell JW, Plano Clark VL. Designing and Conducting Mixed Methods Research, 2nd ed. Thousand Oaks, CA: Sage Publications; 2010.

9. Porcino A, Verhoef MJ. The use of mixed methods for therapeutic massage research. Int J Therapeut Massage Bodywk. 2010;3(1):15-25. 
10. Persons JB, Silberschatz G. Are results of randomized controlled trials useful to psychotherapists? J Consult Clin Psychol. 1998;66(1):126-135.

11. O'Cathain A. Mixed methods research in the health sciences: a quiet revolution [editorial]. J Mixed Meth Res. 2009;3(1):3-6.
Corresponding author: Amanda Baskwill, MSc, BEd, RMT, PC Massage Therapy, School of Hospitality, Recreation \& Tourism, Humber College, 205 Humber College Blvd., Room B104E, Toronto, ON, Canada M9W 5L7

E-mail: amanda.baskwill@humber.ca 